\title{
The Antibacterial Activities of NiO Nanoparticles Against Some Gram-Positive and Gram-Negative Bacterial Strains
}

\author{
Ghazaleh Ilbeigi1" Ashraf Kariminik ${ }^{1 *}$, Mohammad Hasan Moshafi ${ }^{2}$ \\ 'Department of Microbiology, Kerman Branch, Islamic Azad University, Kerman, Iran. \\ ${ }^{2}$ Pharmacology Department, School of Medicine, Kerman University of Medical Sciences and Health Services, Kerman, \\ Iran
}

*Correspondence to

Ashraf Kariminik,

Email: a.kariminik@iauk.ac.ir

Received September 19, 2018 Accepted April 11, 2019 Published online June 30, 2019

Please cite this article as follows: Ilbeigi $G$, Kariminik A, Moshafi $\mathrm{MH}$. The antibacterial activities of $\mathrm{NiO}$ nanoparticles against some gram-positive and gram-negative bacterial strains. Int J Basic Sci Med. 2019;4(2):6974. doi:10.15171/ ijbms.2019.14.

\begin{abstract}
Introduction: Given the increasing rate of antibiotic resistance among bacterial strains, many researchers have been working to produce new and efficient and inexpensive antibacterial agents. It has been reported that some nanoparticles may be used as novel antimicrobial agents. Here, we evaluated antibacterial properties of nickel oxide $(\mathrm{NiO})$ nanoparticles.

Methods: $\mathrm{NiO}$ nanoparticles were synthesized using microwave method. In order to control the quality and morphology of nanoparticles, XRD (X-ray diffraction) and SEM (scanning electron microscope) were utilized. The antibacterial properties of the nanoparticles were assessed against eight common bacterial strains using agar well diffusion assay. The minimum inhibitory concentration (MIC) and minimum bactericidal concentration (MBC) were measured. Antibiotic resistance pattern of the bacteria to nine antibiotics was obtained by Kirby-Bauer disk diffusion method.

Results: The crystalline size and diameter (Dc) of $\mathrm{NiO}$ nanoparticles were obtained 40-60 nm. The nanoparticles were found to inhibit the growth of both gram-positive and gram-negative bacteria with higher activity against gram-positive organisms. Among bacterial strains, maximum sensitivity was observed in Staphylococcus epidermidis with MIC and MBC of 0.39 and 0.78 $\mathrm{mg} / \mathrm{mL}$, respectively. The bacteria had high resistance to cefazolin, erythromycin, rifampicin, ampicillin, penicillin and streptomycin.

Conclusion: $\mathrm{NiO}$ nanoparticles exhibited remarkable antibacterial properties against grampositive and gram-negative bacteria and can be a new treatment for human pathogenic and antibiotic-resistant bacteria.

Keywords: Nickel Oxide Nanoparticles, Bacteria, Antibacterial Activity.
\end{abstract}

\section{Introduction}

Widespread and inappropriate utilization of antibiotics for either preventive or therapeutic purposes has resulted in the emergence of remarkable antibiotic resistance rates worldwide. ${ }^{1}$ The increasing emergence of antibiotic resistance among common bacterial strains has urged the scientific community to seek out new antimicrobial agents. ${ }^{2}$ In general, antibiotic resistant bacteria develop suddenly and may even challenge newly introduced antibiotics. ${ }^{3}$ Two problematic nosocomial pathogens are Pseudomonas aeruginosa and Staphylococcus aureus, both of which commonly exhibit multidrug resistance.
The important role of $P$. aeruginosa has been discovered since $1975 .^{4} \mathrm{~S}$. aureus is also one of the main causes of bacterial infections in hospital settings and community. ${ }^{5} P$. aeruginosa and $S$. aureus are 2 important pathogens, which have antibiotic resistance plasmids to suppress the antibacterial properties of the antibacterial agents. Additionally, antibiotic resistance of Escherichia coli, Klebsiella pneumoniae, Serratia marcescens, Staphylococcus epidermidis, Micrococcus luteus and Bacillus subtilis have also been reported. ${ }^{2,4}$ Therefore, new antibacterial strategies need to be expanded to fight antibiotic resistant bacteria.

(C) 2019 The Author(s); Published by Zabol University of Medical Sciences. This is an open-access article distributed under the terms of the Creative Commons Attribution License (http://creativecommons.org/licenses/by/4.0), which permits unrestricted use, distribution, and reproduction in any medium, provided the original work is properly cited. 
Among the most promising of new antimicrobial agents, nanoparticles have shown potent antibacterial activity. ${ }^{6,7}$ Nanoparticles are very small-scale molecules and have several physical and chemical properties. ${ }^{8}$ Nanoparticles can be metals ions such as $\mathrm{Cu}, \mathrm{Pt}, \mathrm{Zn}, \mathrm{Pd}$, $\mathrm{Ag}, \mathrm{Fe}, \mathrm{Au}$ or metal oxides such as nickel oxide (NiO), $\mathrm{CeO} 2, \mathrm{CuO}, \mathrm{FeO}, \mathrm{Ag} 2 \mathrm{O}$ and $\mathrm{ZnO} .{ }^{9}$ The most important effects of nanoparticles are antibacterial, antiviral, antioxidant, antiparasitic, anti-neoplastic and antiinflammatory effects. ${ }^{10,11}$ The use of nanoparticles as potential antibacterial agents is due to the fact that bacteria are unable to exhibit resistance to the nanoparticles in several cases. ${ }^{3}$ Currently, silver and gold nanoparticles are widely used as antimicrobial agents. ${ }^{12,13}$ However, the information regarding then antibacterial effects of $\mathrm{NiO}$ nanoparticles remains to be completely clarified. Thus, this study was aimed to study the antibacterial effects of $\mathrm{NiO}$ nanoparticles on the $P$. aeruginosa, $S$. aureus, $E$. coli, K. pneumoniae, S. marcescens, S. epidermidis, M. luteus and B. subtilis. Additionally, the techniques used to synthesize $\mathrm{NiO}$ nanoparticles (e.g. hydrothermal, sol-gel, solid-state reaction, electrochemistry, micro emulsions, spray pyrolysis and precipitation methods) are usually complex and expensive. ${ }^{14}$ Therefore, we also introduced a new simple and cheap method to produce $\mathrm{NiO}$ nanoparticles.

\section{Materials and Methods}

Synthesizing and Characterizing the $\mathrm{NiO}$ Nanoparticles $\mathrm{NiO}$ nanoparticles were synthesized using the microwave method as a faster and cheaper strategy than other conventional methods. Briefly, the mixture of $\mathrm{Ni}$ $(\mathrm{OAc})_{2} \cdot 4 \mathrm{H}_{2} \mathrm{O}(1 \mathrm{mM}), \mathrm{NaOH}(2 \mathrm{mM})$ and thiourea $(4$ $\mathrm{mM}$ ) was prepared by dissolving in propylene glycol $(30 \mathrm{~mL})$ and agitated for 20 minutes. The solution was exposed to microwave irradiation in a domestic microwave oven $(2450 \mathrm{MHz}$ at the output powers of 600900 watt for 10 minutes). The obtained powders were washed with distilled water and absolute ethanol. Finally, the precipitate was dried in vacuum $\left(50^{\circ} \mathrm{C}, 48\right.$ hours $){ }^{15}$ The NiO nanoparticles were scanned using XRD (X-ray diffraction) and SEM (scanning electron microscope). XRD patterns of $\mathrm{NiO}$ nanostructure sublimated at $50^{\circ} \mathrm{C}$. SEM imaging of $\mathrm{NiO}$ nanoparticles was performed using SEM (LEO 1455VP, London). Images were prepared using a through lens detector (TLD) in the immersion mode (80000x magnification). The working distance was adjusted at $3 \mathrm{~mm}$ using an accelerating voltage of $10 \mathrm{kV}$. The resolution was adjusted so that the particles could be clearly distinguished from the background. The $\mathrm{NiO}$ nanoparticles size distribution plots were drawn by measuring the diameter of at least 100 nanoparticles in SEM images.

Bacterial Strains

Lyophilized cultures of E. coli (PTCC 1330), K. pneumoniae (PTCC 1053), S. marcescens (PTCC 1621), P. aeruginosa (PTCC 1074), S. aureus (PTCC 1112), S. epidermidis (PTCC 1114), M. luteus (PTCC 1110) and B. subtilis (PTCC 1023) were procured from Persian Type Culture Collection (PTCC), Iran.

\section{Antimicrobial Assay}

The antibacterial properties of $\mathrm{NiO}$ nanoparticle was were by agar well diffusion assay. Bacterial cultures were prepared to match the turbidity of a McFarland 0.5 standard $\left(1.5 \times 10^{8} \mathrm{CFU} / \mathrm{mL}\right)$ in sterile distilled water prior to the assay and inoculated on Mueller-Hinton agar (Merck Company, Germany). Ten serial dilutions yielding concentrations of $100,50,25,12.5,6.253 .12,1.56,0.78$, 0.39 and $0.195 \mathrm{mg} / \mathrm{ml}$ for $\mathrm{NiO}$ nanoparticle were prepared using two-fold dilution. ${ }^{16} \mathrm{Six} \mathrm{mm}$ diameter wells were cut in the culture medium at a distance of $20 \mathrm{~mm}$ from each other and then $20 \mu \mathrm{L}$ of each concentration of nanoparticles was added to each of the 5 wells. The cultures were incubated $\left[\left(36 \pm 1^{\circ} \mathrm{C}\right), 24\right.$ hours] under aerobic condition. Afterwards, the inhibition zone around the wells ( $\mathrm{mm}$ ) was measured. ${ }^{17,18}$ Minimum inhibitory concentration (MIC) and minimum bactericidal concentration (MBC) (i.e. the lowest concentration of nanoparticles inhibiting the bacterial colonies) were determined on Mueller-Hinton agar. ${ }^{19}$ All antibacterial activity tests were performed in triplicate. Antibiotic resistance pattern of bacterial strains was performed by Kirby-Bauer antibiotic sensitivity test according to the guidelines of the Clinical and Laboratory Standard Institute (CLSI) ${ }^{20}$ Mueller-Hinton agar (Merck, Germany) was inoculated with the bacterial suspension in normal saline (0.5 McFarland turbidity). Antibiotic discs (Padtan Teb Co, Iran) were placed on medium cultures. The following antibiotic discs (per unit disc) were applied for performing antimicrobial susceptibility test: cefazolin $(30 \mu \mathrm{g})$, erythromycin $(15 \mu \mathrm{g})$, gentamicin $(10 \mu \mathrm{g})$, rifampicin $(5 \mu \mathrm{g})$, imipenem $(10 \mu \mathrm{g})$, tobramycin $(10 \mu \mathrm{g})$, ampicillin $(10 \mu \mathrm{g})$, penicillin $(10 \mu \mathrm{g})$, and streptomycin $(10 \mu \mathrm{g})$. The resistance data was interpreted according to the guidelines of the CLSI. ${ }^{20}$

\section{Statistical Analysis}

The data was analyzed using one-way ANOVA in the SPSS version 18.0. The $P$ values less than 0.05 were considered as statistically significant.

\section{Results}

Synthesis and Characterization of $\mathrm{NiO}$ Nanoparticles Following the synthesis of $\mathrm{NiO}$ nanoparticles, the appearance of the nanoparticles was assessed by XRD (Figure 1), energy-dispersive analysis of X-ray and SEM.

The crystalline size and diameter (Dc) of nanofibers were obtained $40-60 \mathrm{~nm}$ by analyzing the diffraction patterns of full width of the half maximum (FWHM) using the Debay-Scherer equation (Equation 1): 


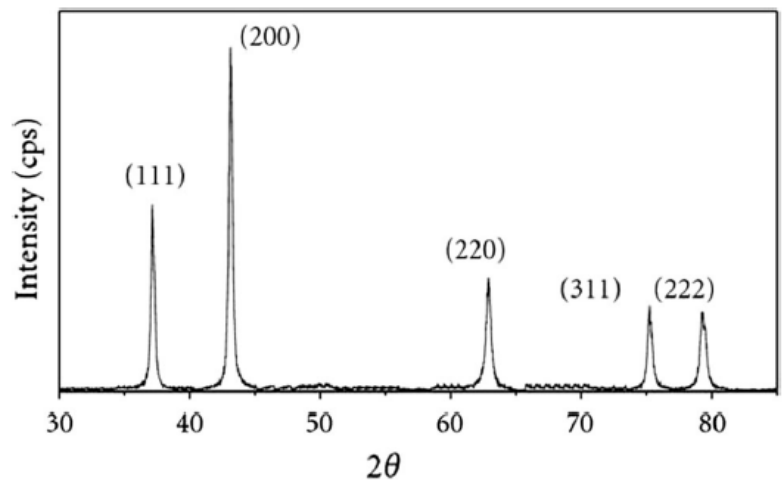

Figure 1. XRD Pattern of $\mathrm{NiO}$ Nanoparticles.

$\mathrm{D}_{\mathrm{xrd}}=0.9 \lambda(57.3) / \mathrm{W}_{\text {size }} \cos \Theta$

Figure 2 illustrates the SEM images of the $\mathrm{NiO}$ nanoparticles sublimated within the range of $50^{\circ} \mathrm{C}$. Image was obtained using the TLD $(80000 \times$ magnification $)$. The $\mathrm{NiO}$ nanoparticles size distribution plots were prepared by measuring the diameter of at least 100 nanoparticles in SEM images. The morphology of all samples was particlelike with an average size of $50 \mathrm{~nm}$. The nanoparticles surface had a relatively good dispersion.

\section{Antibacterial properties of $\mathrm{NiO}$ nanoparticles}

The bacterial growth was determined using agar well diffusion assay in culture media loaded with different concentrations of $\mathrm{NiO}$ nanoparticles by measuring the diameter of inhibition zone. Gram-positive bacteria showed higher sensitivity to $\mathrm{NiO}$ nanoparticles at lower concentrations compared to gram-negative bacteria $(P<0.05$, Figure 3$)$. The results showed that $\mathrm{NiO}$ nanoparticles inhibited bacterial growth in a dosedependent manner (Figure 4). The antibacterial activity (MIC and MBC) of NiO nanoparticles are demonstrated in Table 1. Among bacterial strains, maximum sensitivity was observed in S. epidermidis with MIC of $0.39 \mathrm{mg} / \mathrm{mL}$. Based on antibiogram results, all gram-negative bacteria were resistant to cefazolin, erythromycin and rifampicin and all gram-positive bacteria were resistant to cefazolin.

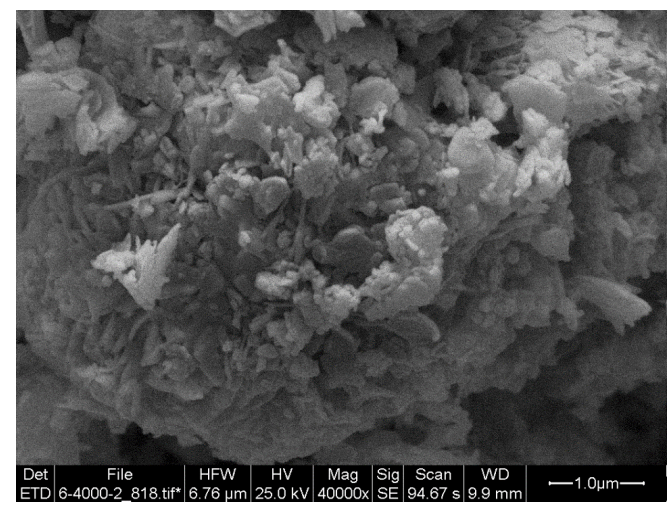

Figure 2. SEM Image of the Synthesized NiO Nanoparticles.

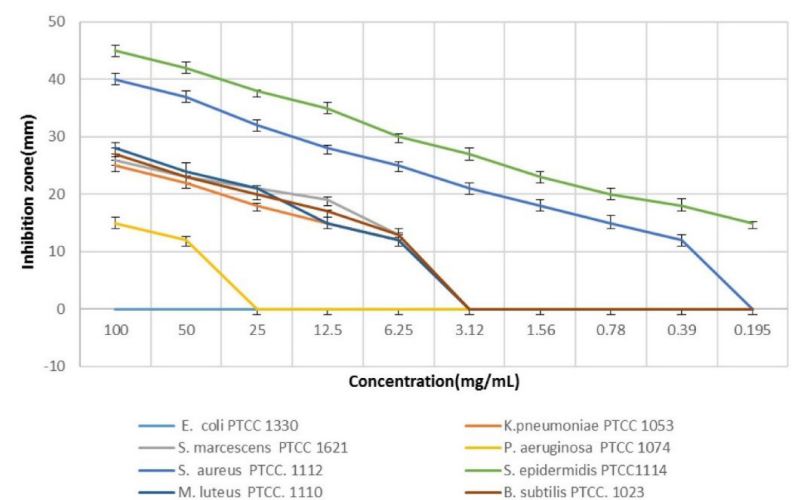

Figure 3. The Antibacterial Properties of Nickel Oxide Nanoparticles Against Various Bacterial Strains.

The antibiotic resistance pattern of the bacterial strains to common antibiotics of different classes is shown in Table 2 .

\section{Discussion}

To overcome the increased resistance of bacteria to common antibiotics and their side effects, there is a need to create new antimicrobial drugs. ${ }^{21}$ How nanoparticles promote their numerous antibacterial effects remains to be sufficiently explained. ${ }^{10}$ There are reports on the antibacterial activities of nanoparticles demonstrated by binding of nanoparticles to bacterial surface, disrupting cell membrane, modulating respiration chain and other permeability-dependent reactions, generating reactive oxygen species (ROS), promoting electrostatic attraction between the positively charged nanoparticles and negatively charged bacterial cells and finally degrading bacterial essential proteins. ${ }^{19,22}$ In this study, we assessed the antibacterial properties of $\mathrm{NiO}$ nanoparticles. The highest inhibitory effect was recorded against gram-positive bacteria, while the growth of gram-negative bacteria was influenced less pronouncedly. This observation can be partly explained by different cellular wall structures of gram-positive and gram-negative bacteria, as well as changes in cellular physiology and metabolism. ${ }^{23}$ The opposite charges of bacteria and nickel ions released from $\mathrm{NiO}$ nanoparticles are thought to cause adhesion and bioactivity due to electrostatic forces. Since bacterial cell walls are negatively charged molecules, they are the potential targets of $\mathrm{Ni}^{2+}$ ions, which are released from $\mathrm{NiO}$ nanoparticles. Gram-negative bacteria are generally less susceptible and more resistant to antimicrobial agents and antibacterial pharmaceuticals than grampositive bacteria mainly due to their impermeable cell wall. The envelope surrounding gram-negative bacteria has two lipid membranes with high concentrations of lipopolysaccharides, lipoprotein and porin channels in the outer leaflet of the outer membrane. ${ }^{24}$ Almost all the components will be affected by multidrug efflux pumps. ${ }^{19}$ Finally, it can be concluded that gram-positive 


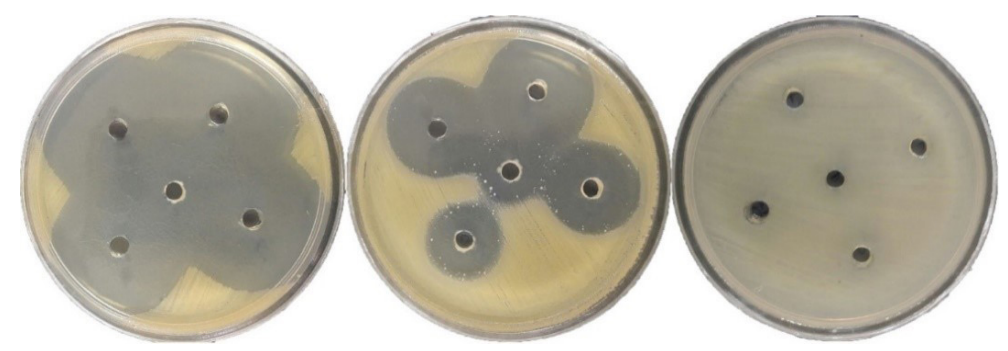

Figure 4. The Antibacterial Properties of Nickel Oxide Nanoparticles Against Staphylococcus epidermidis by Agar Well Diffusion Method.

Table 1. The Minimum Inhibitory Concentration and Minimum Bactericidal Concentration of Nickel Oxide Nanoparticles Against Bacterial Strains

\begin{tabular}{lcc}
\hline Bacteria & MIC $(\mathrm{mg} / \mathrm{mL})$ & $\mathrm{MBC}(\mathrm{mg} / \mathrm{mL})$ \\
\hline Escherichia coli (PTCC 1330) & $\mathrm{MIC}>100$ & $\mathrm{MBC}>100$ \\
Klebsiella pneumoniae (PTCC 1053) & $12.5<\mathrm{MIC} \leq 25$ & 50 \\
Serratia marcescens (PTCC 1621) & $12.5<\mathrm{MIC} \leq 25$ & 50 \\
Pseudomonas aeruginosa (PTCC 1074) & $50<\mathrm{MIC} \leq 100$ & $\mathrm{MBC}>100$ \\
Staphylococcus aureus (PTCC 1112) & $0.78<\mathrm{MIC} \leq 1.56$ & 3.125 \\
Staphylococcus epidermidis (PTCC 1114) & $0.195<\mathrm{MIC} \leq 0.39$ & 0.78 \\
Micrococcus luteus (PTCC 110) & $0.78<\mathrm{MIC} \leq 1.56$ & 3.125 \\
Bacillus subtilis (PTCC 1023) & $3.125<\mathrm{MIC} \leq 6.25$ & 12.5 \\
\hline
\end{tabular}

Table 2. The Antibiotic Resistance Pattern of Bacterial Strains to Antibiotics

\begin{tabular}{|c|c|c|c|c|c|c|c|c|c|}
\hline \multirow{2}{*}{ Bacteria } & \multicolumn{9}{|c|}{ Antibiotics } \\
\hline & $\mathrm{CZ}$ & $\mathrm{S}$ & $\mathbf{P}$ & AM & TB & IM & RA & G & E \\
\hline Escherichia coli (PTCC 1330) & $\mathrm{R}$ & $\mathrm{R}$ & $\mathrm{R}$ & $\mathrm{R}$ & SM & S & $\mathrm{R}$ & SM & $\mathrm{R}$ \\
\hline Klebsiella pneumoniae (PTCC 1053) & $\mathrm{R}$ & $\mathrm{R}$ & $\mathrm{R}$ & $\mathrm{R}$ & $\mathrm{R}$ & $\mathrm{S}$ & $\mathrm{R}$ & $\mathrm{R}$ & $\mathrm{R}$ \\
\hline Serratia marcescens (PTCC 1621) & $\mathrm{R}$ & $\mathrm{R}$ & $\mathrm{R}$ & $\mathrm{R}$ & $\mathrm{R}$ & S & $\mathrm{R}$ & S & $\mathrm{R}$ \\
\hline Pseudomonas aeruginosa (PTCC 1074) & $\mathrm{R}$ & $\mathrm{R}$ & $\mathrm{R}$ & $\mathrm{R}$ & SM & S & $\mathrm{R}$ & $\mathrm{R}$ & $\mathrm{R}$ \\
\hline Staphylococcus aureus (PTCC 1112) & $\mathrm{R}$ & $\mathrm{R}$ & S & $\mathrm{R}$ & SM & S & $\mathrm{R}$ & S & $\mathrm{S}$ \\
\hline Staphylococcus epidermidis PTCC 1114 & $\mathrm{R}$ & $\mathrm{R}$ & S & $\mathrm{R}$ & $\mathrm{R}$ & S & S & R & SM \\
\hline Micrococcus luteus (PTCC 110) & $\mathrm{R}$ & $\mathrm{R}$ & S & $\mathrm{R}$ & $\mathrm{R}$ & S & $\mathrm{R}$ & S & $\mathrm{S}$ \\
\hline Bacillus subtilis (PTCC 1023) & $\mathrm{R}$ & $\mathrm{R}$ & $\mathrm{R}$ & $\mathrm{R}$ & SM & S & S & S & S \\
\hline
\end{tabular}

Abbreviations: S: Sensitive, SM: Semi-sensitive, R: Resistant, CZ: Cefazolin, E: Erythromycin, GM: Gentamicin, RA: Rifampicin, IM: Imipenem, TB: Tobramycin, AM: Ampicillin, P: Penicillin, S: Streptomycin.

bacterial strains are more sensitive to $\mathrm{NiO}$ nanoparticles than the gram-negative bacterial strains because of their membrane structure. Agar well diffusion assay confirmed that $\mathrm{NiO}$ nanoparticles inhibited the growth of bacterial strains dose-dependently. In this regard, the highest antibacterial activity was observed at the $100 \mathrm{mg} / \mathrm{mL}$ concentration. The antibacterial activity of nanoparticles can also be attributed to the nickel ions released from $\mathrm{NiO}$ nanoparticles. The released ions in turn may increase the membrane permeability and promote oxidative stress, which in turn activates cell death pathways. These arguments are supported by previous reports on the antibacterial properties of other nanoparticles such as silver and zinc oxide. ${ }^{25,26}$ In other studies, the antimicrobial properties of nickel nanoparticles synthesized with Ocimum sanctum leaf extract (NiGs) were evaluated against gram-negative and gram-positive pathogenic bacteria and fungi. The NiGs nanoparticles showed higher antimicrobial efficiency against tested microorganisms compared to leaf extract alone and antibiotics. ${ }^{18,19}$ Another investigation showed that bimetallic $\mathrm{Cu}-\mathrm{Ni}$ nanoparticles had a significant effect on Streptococcus mutans, making 
them suitable to be used in dentistry. ${ }^{27}$ In a recent study, hydroxide and $\mathrm{NiO}$ nanoparticles were successfully synthesized by the chemical precipitation, in which, in accordance with our study, $\mathrm{NiO}$ nanoparticles showed inhibitory activity against both gram-positive and gramnegative bacteria with excellent selectivity against grampositive bacteria. ${ }^{14}$ Suresh et al. also suggested that the $\mathrm{NiO}$ nanoparticles exhibited excellent antibacterial and antifungal activities. $^{28}$

\section{Conclusion}

In conclusion, our findings revealed the potential role of $\mathrm{NiO}$ nanoparticles as antibacterial agents, so that they could be used as antiseptic agents in various environmental and biomedical industries. However, the toxicity of these nanoparticles against eukaryotic cells should be explored before approving them as new antibacterial agents.

\section{Ethical Approval}

Not applicable.

\section{Competing interests}

The authors declare no competing interests.

\section{Acknowledgments}

Authors acknowledge all people that help us to perform the research project. The study was derived from an MSc. thesis at Department of Microbiology, Kerman Branch, Islamic Azad University, Kerman, Iran.

\section{References}

1. Khameneh B, Diab R, Ghazvini K, Fazly Bazzaz BS. Breakthroughs in bacterial resistance mechanisms and the potential ways to combat them. Microb Pathog. 2016;95:32-42. doi:10.1016/j.micpath.2016.02.009

2. Slavin YN, Asnis J, Häfeli UO, Bach H. Metal nanoparticles: understanding the mechanisms behind antibacterial activity. J Nanobiotechnology. 2017;15(1):65. doi:10.1186/ s12951-017-0308-Z

3. Wang $\mathrm{L}, \mathrm{Hu} \mathrm{C}$, Shao L. The antimicrobial activity of nanoparticles: present situation and prospects for the future. Int J Nanomedicine. 2017;12:1227-1249. doi:10.2147/ijn.s121956

4. Cross A, Allen JR, Burke J, et al. Nosocomial infections due to Pseudomonas aeruginosa: review of recent trends. Rev Infect Dis. 1983;5 Suppl 5:S837-845.

5. Valaperta R, Tejada MR, Frigerio M, et al. Staphylococcus aureus nosocomial infections: the role of a rapid and lowcost characterization for the establishment of a surveillance system. New Microbiol. 2010;33(3):223-232.

6. Singh R, Lillard JW Jr. Nanoparticle-based targeted drug delivery. Exp Mol Pathol. 2009;86(3):215-223. doi:10.1016/j.yexmp.2008.12.004

7. Huh AJ, Kwon YJ. "Nanoantibiotics": a new paradigm for treating infectious diseases using nanomaterials in the antibiotics resistant era. J Control Release. 2011;156(2):128145. doi:10.1016/j.jconrel.2011.07.002
8. Patil SP, Kumbhar ST. Antioxidant, antibacterial and cytotoxic potential of silver nanoparticles synthesized using terpenes rich extract of Lantana camara L. leaves. Biochem Biophys Rep. 2017;10:76-81. doi:10.1016/j. bbrep.2017.03.002

9. Zare Y, Shabani I. Polymer/metal nanocomposites for biomedical applications. Mater Sci Eng C Mater Biol Appl. 2016;60:195-203. doi:10.1016/j.msec.2015.11.023

10. Teow SY, Wong MM, Yap HY, Peh SC, Shameli K. Bactericidal properties of plants-derived metal and metal oxide nanoparticles (NPs). Molecules. 2018;23(6). doi:10.3390/molecules23061366

11. Stankic S, Suman S, Haque F, Vidic J. Pure and multi metal oxide nanoparticles: synthesis, antibacterial and cytotoxic properties. J Nanobiotechnology. 2016;14(1):73. doi:10.1186/s12951-016-0225-6

12. Beyth N, Houri-Haddad Y, Domb A, Khan W, Hazan R. Alternative antimicrobial approach: nano-antimicrobial materials. Evid Based Complement Alternat Med. 2015;2015:246012. doi:10.1155/2015/246012

13. Panyala NR, Peña-Méndez EM, Havel J. Gold and nanogold in medicine: overview, toxicology and perspectives. J Appl Biomed. 2009;7(2):75-91. doi:10.32725/jab.2009.008.

14. Shanaj BR, John XR. Effect of calcination time on structural, optical and antimicrobial properties of nickel oxide nanoparticles. J Theor Comput Sci. 2016;3(2):149. doi:10.4172/2376-130X.1000149

15. El-Kemary M, Nagy N, El-Mehasseb I. Nickel oxide nanoparticles: Synthesis and spectral studies of interactions with glucose. Mater Sci Semicond Process. 2013;16(6):1747-1752. doi:10.1016/j.mssp.2013.05.018

16. Shahidi Bonjar GH, Karimi Nik A, Heydari MR, et al. Antipseudomona and anti-bacilli activity of some medicinal plants of Iran. DARU J Pharm Sci. 2003;11(4):157-163.

17. Valgas C, de Souza SM, Smânia EF, Smânia A Jr. [Screening methods to determine antibacterial activity of natural products]. Braz J Microbiol. 2007;38(2):369-380. doi:10.1590/S1517-83822007000200034

18. Helan V, Prince JJ, Al-Dhabi NA, et al. Neem leaves mediated preparation of $\mathrm{NiO}$ nanoparticles and its magnetization, coercivity and antibacterial analysis. Results Phys. 2016;6:712-718. doi:10.1016/j.rinp.2016.10.005

19. Jeyaraj Pandian C, Palanivel R, Dhanasekaran S. Screening antimicrobial activity of nickel nanoparticles synthesized using Ocimum sanctum leaf extract. Journal of Nanoparticles. 2016;2016:4694367. doi:10.1155/2016/4694367

20. Clinical and Laboratory Standards Institute (CLSI). Performance standards for antimicrobial susceptibility testing; 16th informational supplement (M100-S16). Wayne, PA, USA: CLSI; 2006.

21. Richter MF, Hergenrother PJ. The challenge of converting Gram-positive-only compounds into broad-spectrum antibiotics. Ann N Y Acad Sci. 2019;1435(1):18-38. doi:10.1111/nyas.13598

22. Reidy B, Haase A, Luch A, Dawson KA, Lynch I. Mechanisms of silver nanoparticle release, transformation and toxicity: a critical review of current knowledge and recommendations for future studies and applications. Materials (Basel). 2013;6(6):2295-2350. doi:10.3390/ 
ma6062295

23. Munita JM, Arias CA. Mechanisms of antibiotic resistance. Microbiol Spectr. 2016;4(2). doi:10.1128/microbiolspec. VMBF-0016-2015

24. Maria-Neto S, de Almeida KC, Macedo ML, Franco OL. Understanding bacterial resistance to antimicrobial peptides: From the surface to deep inside. Biochim Biophys Acta. 2015;1848(11 Pt B):3078-3088. doi:10.1016/j. bbamem.2015.02.017

25. Kim JS, Kuk E, Yu KN, et al. Antimicrobial effects of silver nanoparticles. Nanomedicine. 2007;3(1):95-101. doi:10.1016/j.nano.2006.12.001

26. Jin T, Sun D, Su JY, Zhang H, Sue HJ. Antimicrobial efficacy of zinc oxide quantum dots against Listeria monocytogenes, Salmonella Enteritidis, and Escherichia coli O157:H7.
J Food Sci. 2009;74(1):M46-52. doi:10.1111/j.17503841.2008.01013.x

27. Argueta-Figueroa L, Morales-Luckie RA, ScougallVilchis RJ, Olea-Mejía OF. Synthesis, characterization and antibacterial activity of copper, nickel and bimetallic $\mathrm{Cu}-\mathrm{Ni}$ nanoparticles for potential use in dental materials. Progress in Natural Science: Materials International. 2014;24(4):321-328. doi:10.1016/j.pnsc.2014.07.002

28. Suresh S, Karthikeyan S, Saravanan P, Jayamoorthy K. Comparison of antibacterial and antifungal activities of 5-amino-2-mercaptobenzimidazole and functionalized $\mathrm{NiO}$ nanoparticles. Karbala International Journal of Modern Science. 2016;2(3):188-195. doi:10.1016/j. kijoms.2016.05.001 